\title{
Urbana, moderna e midiática: a construção comunicacional da imagem de Juazeiro do Norte
}

\author{
Urban, modern and mediatic: communicational construction of the \\ image of Juazeiro do Norte
}

\section{Elane Abreu de Oliveira}

Docente da Universidade Federal do Cariri (UFCA). Doutora em Comunicação e Cultura pela Universidade Federal do Rio de Janeiro (ECO-UFRJ). E-mail: elane.abreu@ufca.edu.br

Submetido em 08 de Agosto de 2019 Aceito em 30 de Outubro de 2019

\section{RESUMO}

Neste artigo, a cidade de Juazeiro do Norte é investigada a partir dos ícones de lugares expressos na logo da gestão municipal. A questão é: o que os ícones comunicam de uma nova representatividade da cidade para além da religiosidade já conhecida? 0 percurso metodológico inclui pesquisa exploratória sobre a logo através de peças de comunicação da Prefeitura, entrevistas e análise de imagens midiáticas. $O$ estudo é fundamentado numa discussão sobre a imagem da cidade e o branding urbano. Um resultado observado nessa investigação foi a construção discursiva e comunicacional da cidade dirigida à modernidade arquitetônica e ao desenvolvimento econômico.

PALAVRAS-CHAVE: Comunicação urbana; imagem; branding; Juazeiro do Norte.

\section{ABSTRACT}

In this paper, the city of Juazeiro do Norte is investigated from the icons of places portrayed in the municipal government logo. The question is: what do the icons communicate of a new representativeness of the city beyond its well-known religiosity? The methodological skills include exploratory research on the logo through communicational pieces issued by City Hall, interviews, and analysis of media images. The study is based on a discussion about the image of the city and urban branding. An observed result in this investigation was a discursive and communicational construction of the city directed to architectural modernity and economic development.

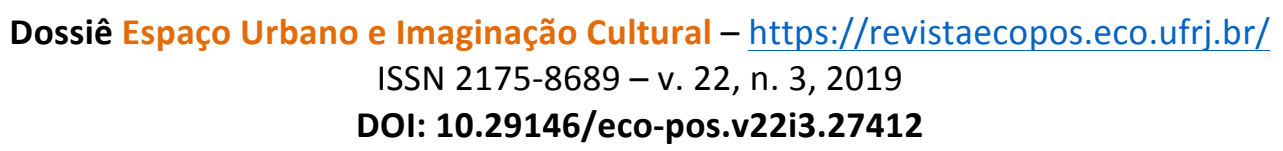


KEYWORDS: Urban communication; image; branding; Juazeiro do Norte.

\section{RESUMEN}

En este artículo, la ciudad de Juazeiro do Norte es investigada a partir de los iconos de lugares expresados en el logo de la gestión municipal. La cuestión es: ¿qué los iconos comunican de una nueva representatividad de la ciudad más allá de la religiosidad ya conocida? El recorrido metodológico incluye investigación exploratoria acerca del logo a través de piezas de comunicación de la municipalidad, entrevistas y análisis de imágenes mediáticas. El estudio se basa en una discusión sobre la imagen de la ciudad y el branding urbano. Un resultado señalado en esa investigación fue la construcción discursiva y comunicacional de la ciudad dirigida a la modernidad arquitectónica y al desarrollo económico.

PALABRAS-CLAVE: Comunicación urbana; imagen; branding; Juazeiro do Norte.

\section{Introdução}

As cidades, lembradas por seus ícones monumentais visivelmente situados no espaço, elaboram repertórios mnemônicos precisos. Assim ocorre com exemplos globais, como a Paris da Torre Eiffel ou a Nova York da Estátua da Liberdade, bem como com o exemplo nacional do Rio de Janeiro do Cristo Redentor, estampado nos cartões-postais. Já a cidade de Juazeiro do Norte, no interior do estado do Ceará, é recorrentemente lembrada pelo monumento de Padre Cícero, figura emblemática na formação da cidade e representação icônica consagrada pela devoção popular.

Com o passado alicerçado em terras rurais, após a seca de 1877 Juazeiro teve o incentivo de Padre Cícero para transformação do vilarejo em lugar de trabalho, expansão da plantação de mandioca e abastecimento familiar, dentre outros incrementos estimulados pela fé. A aliança entre "trabalho e fé" fez da cidade um lugar de atração de devotos do Padre vindos de diversas localidades, caracterizando o território como lugar de peregrinações e espiritualidade, bem como pela dinâmica de transformação econômica. 0 líder espiritual teve influência na ascensão do povoado a município em 1911, sendo o primeiro prefeito da cidade,

Dossiê Espaço Urbano e Imaginação Cultural - https://revistaecopos.eco.ufrj.br/

ISSN 2175-8689 - v. 22, n. 3, 2019

DOI: $10.29146 /$ eco-pos.v22i3.27412 
e a tradição popular que envolve sua figura - controversa nos aspectos políticos faz da sua imagem, até hoje, uma forte representação do lugar (Araújo, 2011; Neto, 2009).

No ano de 2017, a Prefeitura de Juazeiro do Norte lançou uma nova marca e identidade visual da gestão municipal em que outras representações de lugares da cidade surgem ao lado do ícone Padre Cícero. A partir disso, questionamentos surgem: que outros lugares são visualmente apresentados? 0 que estes comunicam sobre uma nova representatividade de Juazeiro do Norte? Conhecida pelo apelo visual e mnemônico do monumento de Padre Cícero, a cidade, nesta marca mais recente, aparece representada visualmente pela silhueta do Padre e pelo formato de quatro outros lugares: o Luzeiro do Sertão, o Unique Condominium, o Memorial Padre Cícero e a Igreja do Socorro. Estes lugares sugerem discursos, além da religiosidade, em que os acontecimentos arquitetônicos marcam presença, sendo forte o vínculo com modelos globais de cidade.

O objetivo deste artigo é discutir as representações urbanas de Juazeiro que partem dos lugares - acontecimentos visuais - sugeridos pela nova marca da gestão municipal, com foco nos novos marcos arquitetônicos. 0 percurso metodológico se compõe da pesquisa exploratória sobre a logo através dos canais de comunicação da Prefeitura, de entrevistas com a assessora de comunicação e com o designer da marca, e de imagens midiáticas da imprensa local. Como fundamentação, é articulado um estudo teórico-analítico sobre a imagem da cidade (McQuire, 2010; Cacciari, 2010; Peixoto, 2004; Ferrara; 2000) e o processo de branding urbano (Guerreiro, 2013; Jaguaribe, 2011; Sánchez, 2010), destacando os marcos representativos e os novos elementos urbanos que surgem vinculados à comunicação urbano-visual de Juazeiro do Norte.

Dossiê Espaço Urbano e Imaginação Cultural - https://revistaecopos.eco.ufrj.br/

ISSN 2175-8689 - v. 22, n. 3, 2019

DOI: 10.29146/eco-pos.v22i3.27412 


\section{Comunicação, imagem e cidade: alguns pressupostos}

As cidades tecem diariamente modos de vida, de interação com os espaços e de percepção visual dos lugares que a constituem. As imagens que frequentemente associamos às cidades estão impregnadas de forças sígnicas e de construções visuais prévias elaboradas com a finalidade de sintetizar significados urbanos. Os diferentes suportes midiáticos auxiliam na consolidação de visões de cidade, ou seja, de representações urbanas que buscam organizar experiências muitas vezes difusas e caóticas dos espaços-tempos das cidades, como pontua Scott McQuire (2010). Para o autor, a mídia proporciona representações, ou seja, discursos construídos, fiéis ou não ao mundo exterior.

Por estarem em contato com dinâmicas globalizadas, as cidades são desafiadas a manterem traços particulares ante os instrumentos de homogeneização das diferenças. Eis o desafio colocado para urbanistas e profissionais da comunicação. Apesar de McQuire (2010) acreditar que a cidade do século XXI é menos simbolizada por arranha-céus do que por supervias, Juazeiro do Norte, cidade a que se refere este artigo, é midiaticamente compreendida por discursos baseados no crescimento espacial dos edifícios. Há apelo visual e de consumo na imagem do espaço urbano construído, e nele se investe o trabalho de comunicadores, arquitetos, empresários e gestores públicos.

Nelson Brissac Peixoto (2004) tem olhar crítico para o que chama de uma imposição de "retórica da imagem", que incorpora estratégias estéticas que desvinculam o espaço urbano de seus fluxos espaciais amplos, reafirmando a síntese publicitária. Para o autor, há mediações de um "aparato publicitário que tende a tudo converter em cenografia e simulacro", e estas corroboram uma "espacialidade estetizada”. É sintomático das dinâmicas contemporâneas esse tipo de conversão dos lugares em imagens consumíveis, e a esse processo é necessário lançarmos um olhar atento. Mediante a seleção e promoção de alguns aspectos visíveis das cidades, a comunicação urbana baseada no "simulacro" tende a excluir

\footnotetext{
Dossiê Espaço Urbano e Imaginação Cultural - https://revistaecopos.eco.ufrj.br/

ISSN 2175-8689 - v. 22, n. 3, 2019

DOI: $10.29146 /$ eco-pos.v22i3.27412
} 
outras configurações imagéticas, menos formais e previsíveis. Esse processo de vínculo entre imagem e cidade encampado por gestão municipal e profissionais de comunicação é possível de ser percebido em Juazeiro do Norte e será adiante explanado.

Firmar uma identidade para as cidades é necessário tanto nos processos de gestão governamental como nas mediações por ícones publicitários. De cada lugar, significados socioculturais são extraídos como forma de sínteses das imagens urbanas. Lucrécia Ferrara (2000) destaca que os significados urbanos afetam nossa percepção e que sentidos de cidade locais e globais coexistem. Tendo como exemplo São Paulo, a autora sublinha a "dimensão sígnica de um ícone" (Ferrara, 2000, p. 90) como necessária à criação de uma identidade para a cidade, tendo em vista as mudanças pelas quais passam os espaços urbanos. 0 urbano se torna inteligível pela imagem, signo visual, mas os sentidos do urbano não se esgotam na complexidade de experiências dos indivíduos. Principalmente com o advento da múltipla "cidade virtual" e suas possibilidades de sentido, imagem e imaginário estão em contínuo processo de produção. Enquanto a imagem fixa um sentido, para Ferrara (2000), o imaginário transgride um significado unificado, uma vez que é permeado por apropriações sociais. A imagem da cidade, icônica e visual, inclusive, pode ser reelaborada a partir dos sentidos desencadeados pelo imaginário.

A partir do que se apreende por McQuire (2010), Peixoto (2004) e Ferrara (2000), a imagem da cidade "arranha-céu", "estetizada" e "icônica", contrasta com a multiplicidade de significados que fogem à previsibilidade de estratégias midiáticas sintetizadoras. No entanto, é pertinente entendermos como se dá o processo de construção de uma imagem urbana consumível, considerando o que ela agrega ou exclui de um imaginário urbano mais amplo. Para esta compreensão, destaca-se o branding urbano (Guerreiro, 2013; Jaguaribe, 2011; Sánchez, 2010), termo que se dirige ao processo estratégico de criação de uma imagem urbana

Dossiê Espaço Urbano e Imaginação Cultural - https://revistaecopos.eco.ufrj.br/

ISSN 2175-8689 - v. 22, n. 3, 2019

DOI: $10.29146 /$ eco-pos.v22i3.27412 
competitiva, vendável e consumível frente à lógica econômica capitalista. Aspectos dessa construção imagética via branding são discutidos por alguns autores.

Ver a cidade como produto é um dos desígnios do branding de cidades. Conforme Rúben Guerreiro (2013, p. 9), o branding "fornece a base para identificar e unificar uma série de imagens pretendidas para a cidade e os significados a si atribuídos". Este processo de unificação pode contribuir para a melhoria da imagem e competitividade das cidades. Por comunicar atributos do que torna determinada cidade única, com identidade distinta de outras, o branding atua na composição de uma imagem competitiva ante a concorrência. A cidade é então vista como produto distinto dentre os demais, numa lógica identitária e mercadológica, como acontecem com as marcas de produtos.

Para Beatriz Jaguaribe (2011, p.330), “o branding urbano é uma invenção deliberada que faz uso de uma variedade de repertórios e representações para maximizar lucros e recursos". Ou seja, nas economias capitalistas atuais, a invenção de uma imagem da cidade "empacota" sentidos vendáveis do lugar, e isso se dá numa ação coletiva de setores da administração pública, empresários, arquitetos/urbanistas, bem como profissionais de publicidade. Com base na seleção de representações e repertórios do lugar, esta imagem se constrói, ressaltando características identitárias que a tornam distinta e de forte apelo localglobal.

O crucial no processo de branding é vender uma imagem da cidade para que ela possa ser recipiente de recursos, investimentos, turismo e ganhos econômicos. Cada cidade terá que inventar e apostar nas suas próprias estratégias de branding levando em conta uma adequação entre seus repertórios e seus slogans. (JAGUARIBE, 2011, p. 330-331).

Cada cidade, dessa forma, torna-se suscetível aos desígnios estratégicos de branding, sejam elas grandes metrópoles ou cidades de menor escala com atrativos locais. Juazeiro do Norte, cidade do interior do Ceará conhecida por sua mística religiosa e pela cultura popular da região, entra nesse entendimento de uma

\section{Dossiê Espaço Urbano e Imaginação Cultural - https://revistaecopos.eco.ufrj.br/ \\ ISSN 2175-8689 - v. 22, n. 3, 2019 \\ DOI: $10.29146 /$ eco-pos.v22i3.27412}


"invenção" lucrativa ao passo que a administração pública da cidade recorre a ícones e imagens como forma de criar uma representação urbana consumível. A identidade visual da gestão municipal capta elementos icônicos da cidade como forma de "empacotamento" de lugares turísticos junto a marcos arquitetônicos que se destacam na paisagem.

O esforço seletivo do branding, ou as estratégias de city marketing, para Fernanda Sánchez (2010), é pautado numa "reinvenção" de cidade, liderada por elites políticas e econômicas. Esse esforço recai muitas vezes em "imagens estereotipadas" de recortes de territórios que provocam visões distorcidas e simplificadas do lugar. Megaeventos como as Olimpíadas, por exemplo, são trabalhados como formas de exportar imagens das cidades-sede, fomentadas pelo ideário de desenvolvimento e ganho de visibilidade no mercado mundial. A valorização do capital das cidades, através do branding, é expressa pela transformação do espaço em mercadoria, e esta ganha corpo nas representações eleitas.

A produção do espaço-mercadoria envolve também a produção de representações que o acompanham. Esse espaço é concebido como lugar onde o privado se arma, produzindo signos que parecem realizar desejos e fantasias de consumo moldados por valores da "mundialidade" (SÁNCHEZ, 2010, p. 23).

A imagem estereotipada do interior nordestino é midiaticamente construída por discursos de manchetes noticiosas, muitas vezes associados à seca e carência do sertão. Esta imagem se confronta com a experiência de muitos que habitam o território. Juazeiro do Norte, cidade do Cariri cearense em progressiva urbanização, com população estimada de 270.383 habitantes (dados de 2017 do IBGE), é exemplo de como a imagem urbana do interior passa por reinvenções. A marca atual da prefeitura da cidade aciona representações que nada resguardam de uma associação a imagens de privação sertaneja. 0 branding da cidade "empacota" uma imagem de religiosidade e desenvolvimento econômico, unindo

Dossiê Espaço Urbano e Imaginação Cultural - https://revistaecopos.eco.ufrj.br/

ISSN 2175-8689 - v. 22, n. 3, 2019

DOI: 10.29146/eco-pos.v22i3.27412 
traços locais e modelos mundiais. Esses valores são destacados em signos de fé e edifícios/marcos visuais de grande escala que comparecem na marca da atual gestão municipal.

É preciso destacar a forte parceria público-privado na construção da imagem da cidade, sem esquecer a dimensão "estetizada" e "icônica" /"arranhacéu" nela presente (Peixoto, 2004; Ferrara, 2000; McQuire, 2010). A síntese imagética comunica repertórios eleitos direcionados ora ao turismo, ora ao logro arquitetônico, distanciando-se de uma imagem de passado ou atraso. A construção publicitária da imagem urbana, como apontado anteriormente, tende a deixar de fora sentidos identitários elaborados no imaginário dos próprios habitantes, sendo estimulada por vínculos mais vendáveis. Nessa direção, é perceptível que a imagem de Juazeiro conduzida pelo branding (Guerreiro, 2013; Jaguaribe 2011; Sánchez, 2010) busca valorizar a desenvoltura dos grandes edifícios, inclusive os de iniciativa privada, como ícones.

Os edifícios, conforme salienta Massimo Cacciari (2010), sugerem padrões globais de cidade. Os espaços construídos demarcam e geram imagens de desenvolvimento, sinalizando a rápida transformação do território. Como "acontecimentos" que são colocados no território metropolitano, os edifícios se dão, acontecem no espaço, desvinculando-se da persistência antiga. Conforme o autor, a "cidade pós-metrópole" se organiza conforme medidas temporais para acontecimentos, que surgem, por exemplo, na forma de novas construções que ocupam o espaço. Um acontecimento se dá como marcante até que outro surja. Neste sentido, podemos entender, como exemplo de "edifício-acontecimento", as torres gêmeas em Nova York. 0 atentado terrorista que levou ao chão as torres em 2001 fez com que outros prédios acontecessem na paisagem.

Em Juazeiro do Norte, acontecimentos arquitetônicos têm marcado o espaço urbano, projetando uma imagem de desenvolvimento alinhada a modelos globais de cidade. É relevante pontuar que a gestão municipal, ao elaborar sua marca, incluiu um grande edifício da cidade, o que nos fez questionar sobre como

Dossiê Espaço Urbano e Imaginação Cultural - https://revistaecopos.eco.ufrj.br/

ISSN 2175-8689 - v. 22, n. 3, 2019

DOI: 10.29146/eco-pos.v22i3.27412 
se deu a eleição desse e de outros ícones presentes na identidade visual da prefeitura. Constantemente associada à imagem de Padre Cícero, a cidade sintetizada nos cinco ícones da marca une elementos religiosos e arquitetônicos, expandindo a representação clássica do "Padim" (Padre Cícero).

A atenção às representações imagéticas/sígnicas urbanas é citada por Óscar Moreno e Sandra Meléndez-Labrador (2017, p.215) no que tange ao conhecimento sobre as configurações simbólicas dos espaços das cidades. Os autores afirmam que "a cidade emite signos, e para habitá-la, para vivê-la, deve-se saber interpretar os ícones, signos e símbolos que estão nas gramáticas que a compõem"1. Por entender que a comunicação elaborada pela Prefeitura de Juazeiro do Norte emite signos visuais através de sua marca (logo), é pertinente trazermos à tona e discutir as representações ali eleitas. A comunicação urbana é construída, dentre outros, por vínculos estabelecidos pelos ícones da gramática visual da gestão municipal e pela presença destes na mídia local, gerando discursos.

A gramática destes itens, que se estabelece associada a um branding urbano, sinaliza para inclusões e exclusões de repertórios imagéticos. Juazeiro do Norte, cidade do interior, é continuamente associada ao turismo religioso, ao "roteiro da fé", às romarias, que trazem penitentes de diversos outros lugares. $\mathrm{Na}$ "cidade-santuário", como pontua Maria Araújo (2011, p.96), a devoção ao Padre Cícero fez dele uma "marca", que "mobiliza uma grande magnitude de riquezas materiais e imateriais em torno de sua imagem e do seu nome". Não por acaso, a marca construída para a atual gestão municipal, do prefeito Arnon Bezerra, traz o "Padim" entre seus ícones, ratificando seu poder simbólico. Porém, além desta ligação com a fé, o que podemos extrair de novas representações presentes na marca? Que outros ideários são comunicados por representações de “acontecimentos” no espaço construído? É o que discutiremos a seguir.

\footnotetext{
1 Tradução livre de: "La ciudad emite signos y para habitarla, vivirla, se deben saber interpretar los íconos, señales y símbolos que hay en las gramáticas que la componen".
}

Dossiê Espaço Urbano e Imaginação Cultural - https://revistaecopos.eco.ufrj.br/

ISSN 2175-8689 - v. 22, n. 3, 2019

DOI: $10.29146 /$ eco-pos.v22i3.27412 


\section{Juazeiro do Norte: implicações comunicativas da imagem urbana}

Juazeiro do Norte, "capital da fé”, "cidade-santuário", é conhecida como metrópole da região do Cariri, no Ceará. Traduzi-la e sintetizá-la visualmente a partir de ícones (personagens, lugares ou monumentos) é um desafio que envolve profissionais de comunicação e designers, além dos próprios gestores da prefeitura. Nessa construção conjunta, para a elaboração de uma nova marca da cidade, lembremos os esforços dirigidos ao branding urbano (Guerreiro, 2013; Jaguaribe, 2011; Sánchez, 2010), que tem como mote a invenção de uma imagem da cidade vendável e lucrativa, baseada em representações e repertórios do lugar. Setores da administração pública juntamente com empresários, urbanistas, arquitetos e profissionais de comunicação e publicidade atuam nesta construção imagética.

Para explorar a construção da marca da Prefeitura de Juazeiro do Norte (Figura 1), lançada em 2017, materiais institucionais foram consultados, tanto impressos quanto digitais. No segundo semestre de 2017, foram realizadas entrevistas com dois profissionais ligados à Prefeitura e sua comunicação visual: a assessora de imprensa e o designer da $\log ^{2}$. Com as respostas dos profissionais, foram obtidas informações mais precisas sobre as decisões e estratégias pensadas para a representatividade da marca e seus ícones, que a seguir serão discutidas.

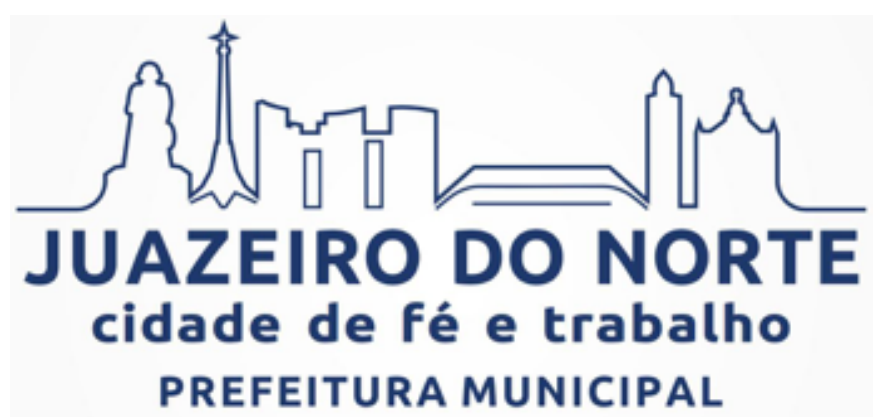

Figura 1: Marca (logo) da prefeitura de Juazeiro do Norte - CE. Fonte: site da prefeitura.

${ }^{2}$ A assessora de imprensa foi entrevistada pessoalmente no dia 08 de agosto de 2017 e o designer da logo respondeu às questões por email no dia 06 de outubro de 2017.

Dossiê Espaço Urbano e Imaginação Cultural - https://revistaecopos.eco.ufrj.br/

ISSN 2175-8689 - v. 22, n. 3, 2019

DOI: $10.29146 /$ eco-pos.v22i3.27412 
A logo apresenta a silhueta (forma) de cinco lugares da cidade, respectivamente: a estátua do Padre Cícero, o Luzeiro do Sertão, o Unique Condominium, o Memorial Padre Cícero e a Igreja do Socorro. Estes cinco ícones formam, por linhas, o traçado conjunto da nova marca, misturando lugares do "roteiro da fé" (Figura 2) com outras representações. 0 monumento de Padre Cícero, clássico do turismo, junto ao Memorial e a Igreja (ou Capela) do Socorro são elementos ligados à religiosidade, já que se vinculam à figura do "Padim". No Memorial, há um acervo de peças, imagens e documentos vinculados à história do "santo popular". Já na Capela do Socorro encontram-se seus restos mortais (túmulo), e é um lugar onde se celebram missas durante as romarias.

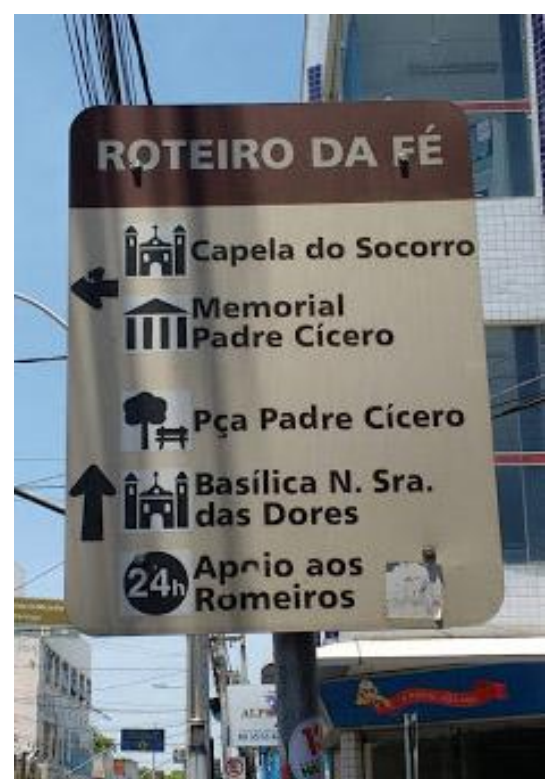

Figura 2: Placa do "roteiro da fé" na rua São Pedro - Centro de Juazeiro do Norte. Fonte: acervo da autora.

A marca não se distancia, em sua estética publicitária, de diversas outras, como nos exemplos de Aparecida - SP e Triunfo - PE. Em ambas, é valorizada a silhueta das formas construídas, incluindo formas de templos religiosos. Os elementos da logo que não estão no circuito da fé (Luzeiro e Unique Condominium 
- Quadro 1) são os que chamam mais atenção, uma vez que se dirigem aos "acontecimentos" de que fala Cacciari (2010). Sendo marcos visuais de grande escala na paisagem do recente Juazeiro, eles acenam para novas intenções de representação vinculadas à cidade. 0 Unique Condominium é o ícone que mais enfaticamente se diferencia dos outros quatro eleitos para a marca, já que é um alto edifício de iniciativa privada.

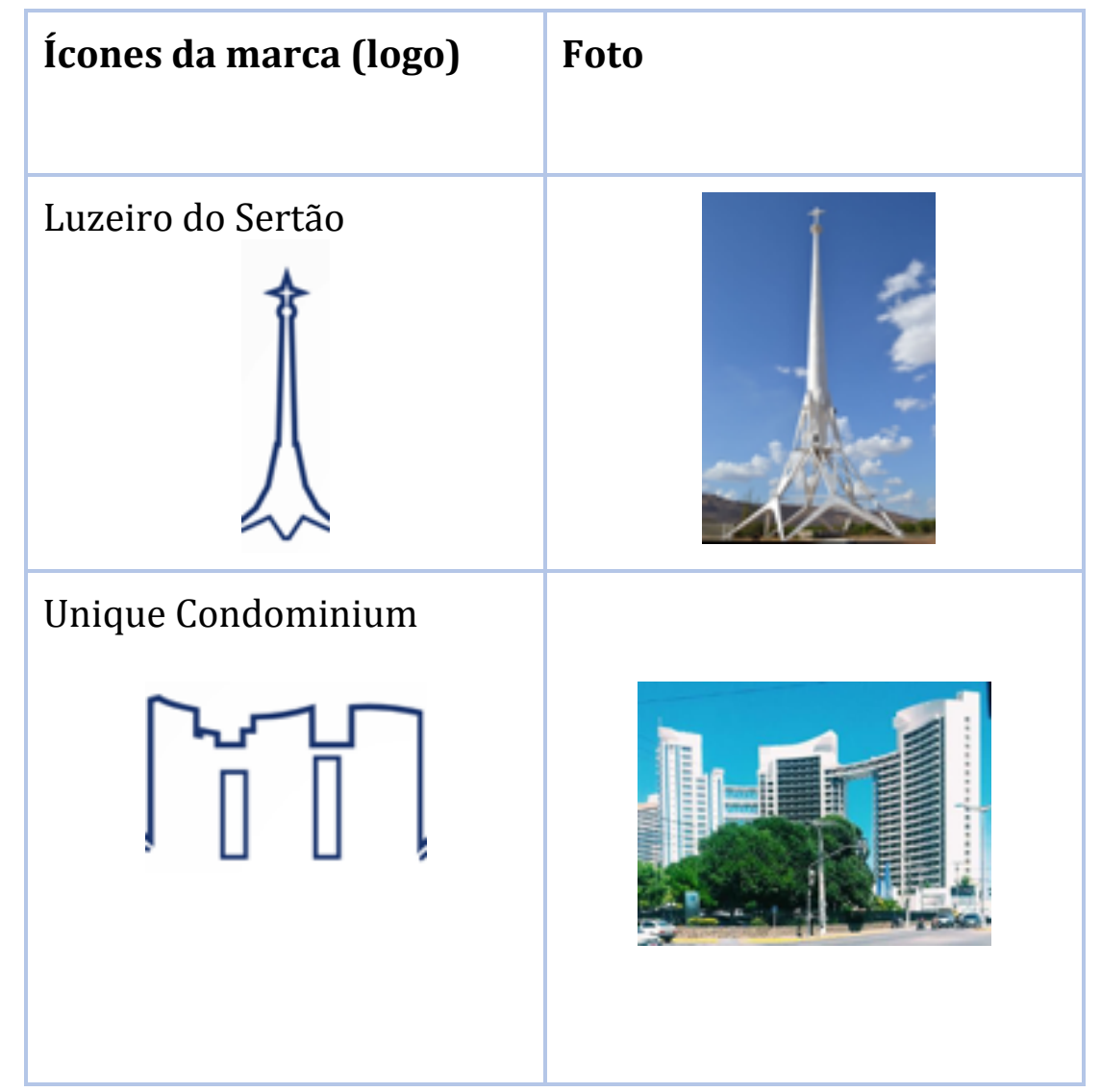

Quadro 1: Quadro comparativo de ícones da marca da Prefeitura - Fonte: acervo da autora.

Com 111,5 metros de altura no centro da cidade, o Luzeiro do Sertão (ou Luzeiro do Nordeste, como também é chamado) é uma torre metálica, idealizada como templo, ligada ao marco da virada do milênio e dos 500 anos do descobrimento do Brasil. Inaugurado em 2005, sua base possui cinco apoios, o corpo é um único bastão de ferro e a extremidade é uma cruz. De locais mais distantes e altos da cidade, como o Horto onde se encontra a estátua de Padre

Dossiê Espaço Urbano e Imaginação Cultural - https://revistaecopos.eco.ufrj.br/

ISSN 2175-8689 - v. 22, n. 3, 2019

DOI: $10.29146 /$ eco-pos.v22i3.27412 
Cícero, é possível avistá-lo, sendo ponto que marca o espaço. Seu arquiteto, Luiz Deusdara3, cita a seguinte definição para a construção: "uma catedral para o sertanejo: sem paredes, sem portas, sem teto, tendo o infinito do céu como seu invólucro". Tamanha construção se tornou "acontecimento" peculiar na paisagem da cidade. Contudo, após a sua inauguração, transformou-se num local abandonado, vazio, não fazendo parte do circuito turístico.

A presença do Luzeiro como "acontecimento" visual sublinha a imagem de cidade que transmite a projeção do espaço construído, mas sem uma função social ativa. A grande torre é um adorno do território metropolitano, que ajuda a ressaltar a modernidade da cidade. 0 lugar, sem trânsito de pessoas, enfatiza a visão puramente formal de um símbolo fincado no espaço. Diferentemente dos lugares do "roteiro da fé", não há trânsito de romeiros ou eventos que congreguem pessoas. É um monumento público vazio de prática.

O Unique Condominium surpreende ainda mais por sua presença como ícone na marca governamental. 0 prédio é um investimento empresarial na cidade e tem uma arquitetura altamente moderna, formada por três torres no bairro Triângulo, sendo a mais alta com 27 andares. 0 edifício começou a ser construído em 2013 para conter um centro empresarial além de uma ala residencial e, em dias atuais, ainda prospecta vendas de seus espaços. Vinculado à construtora Base, é presença da aliança entre público e privado, estimuladora do processo de branding. Sua forma se tornou fortemente midiática, "inspirada nos arranha-céus de Dubai, conhecida no mundo inteiro por sua arquitetura ousada" 4 . Como imagem vendável, o condomínio imponente se estabeleceu como ícone de progresso.

Em processo de verticalização, Juazeiro demarca seu horizonte com a ousadia de edifícios possíveis de serem vistos a longa distância. A inclusão do

\footnotetext{
3 A menção à obra foi retirada do perfil do arquiteto no Instagram. Disponível em: https://www.instagram.com/p/Bkvv_0sAvDp/. Acesso em: 10 jun. 2019.

4 As especificações do prédio são descritas no site da construtora. Disponível em: http://baseeng.com.br/empreendimento/unique-condominium/. Acesso em: 10 jun. 2019
}

Dossiê Espaço Urbano e Imaginação Cultural - https://revistaecopos.eco.ufrj.br/

ISSN 2175-8689 - v. 22, n. 3, 2019

DOI: 10.29146/eco-pos.v22i3.27412 
Unique na marca da gestão pública nos provoca a perceber esse "acontecimento" como ponto-chave da nova imagem urbana do interior estimulada pela Prefeitura. Um edifício, com suas linhas e contornos geométricos associados ao futuro, sustenta a ideia de cidade moderna, distanciada do passado, do atraso. Nada mais característico do "acontecimento" do que o surgimento de edifícios na cidade, que se dão no espaço de outras construções, abrindo caminhos para que outros surjam. Ao lado do Unique, logo aconteceram outros. Por ser empreendimento privado, não há uso irrestrito por parte do público da cidade, sendo um ícone urbano sem atrativo social. 0 casamento público-privado nas práticas da gestão municipal sinaliza para uma imagem urbana de uma Juazeiro arquitetonicamente e economicamente desenvolvida como atrativo de negócios.

A assessora afirmou que a inspiração para a logo veio de uma camiseta trazida da Europa pelo secretário de Cultura do município. Segundo ela, "ele viu o desenho em uma camisa que inspirou os traços e a elaboração da logo, e essa representação veio trazer essa coisa da urbe e da cidade". Destaca-se uma perspectiva de Juazeiro como cidade ligada à imagem de "urbe", parâmetro que a situa dentro de uma visão global de cidade moderna. A profissional ressalta a confluência de tempos: "Se você olhar para os traços que são feitos, eles trazem o moderno, mas ao mesmo tempo resgatam a história e os símbolos, como a estátua do Padre Cícero, que é um símbolo muito forte da cidade e do contexto que ela incorpora, como a religiosidade".

O designer da marca destacou que a referência inspiradora da logo "não era algo exclusivo desta cidade, pois este design de símbolos urbanos em silhueta já é utilizado há tempos no design para representar grandes metrópoles". A ideia de imagem da cidade atenta aos padrões mundiais e metropolitanos se confirma no diálogo sobre o design da logo. Ligada aos marcos arquitetônicos, a eleição dos cinco ícones (Padre Cícero, Luzeiro do Sertão, Unique, Memorial Padre Cícero e Igreja do Socorro) é justificada pelo designer pela facilidade de reconhecimento. “Estes símbolos foram utilizados por serem arquitetonicamente marcantes e de

Dossiê Espaço Urbano e Imaginação Cultural - https://revistaecopos.eco.ufrj.br/

ISSN 2175-8689 - v. 22, n. 3, 2019

DOI: $10.29146 /$ eco-pos.v22i3.27412 
fácil reconhecimento, cada um simbolizando e representando a fé, o desenvolvimento urbano e os símbolos visualmente mais marcantes da cidade".

Esta construção discursiva conforme a importância visual e comunicacional dos traços arquitetônicos tem sido trabalhada também por imagens midiáticas divulgadas por veículos locais. Exemplos disso são as construções anunciadas pela revista "O Povo Cariri", no final de 2018: o edifício "Spazio Bezerra de Menezes" (Figura 3) e o shopping "La Plaza Mall" (Figura 4). Ambos acontecimentos dão ênfase ao sentido de cidade espacialmente e economicamente crescente. 0 "edifício mais alto" do estado, com duas torres de 100 metros cada, é um residencial localizado em bairro nobre, a Lagoa Seca, e tem vista para a chapada do Araripe. A construção marca visualmente a paisagem, tem ênfase midiática no recorde em altura e é representativa dos altos investimentos econômicos em empresas de construção civil, vinculadas à verticalização da cidade. O shopping, por outro lado, também sublinha a ostensiva relação da imagem urbana com o desenvolvimento do espaço para o comércio, sendo "mais um" a oferecer traços modernos na dinâmica da cidade. 0 empreendimento também se situa no bairro Lagoa Seca.
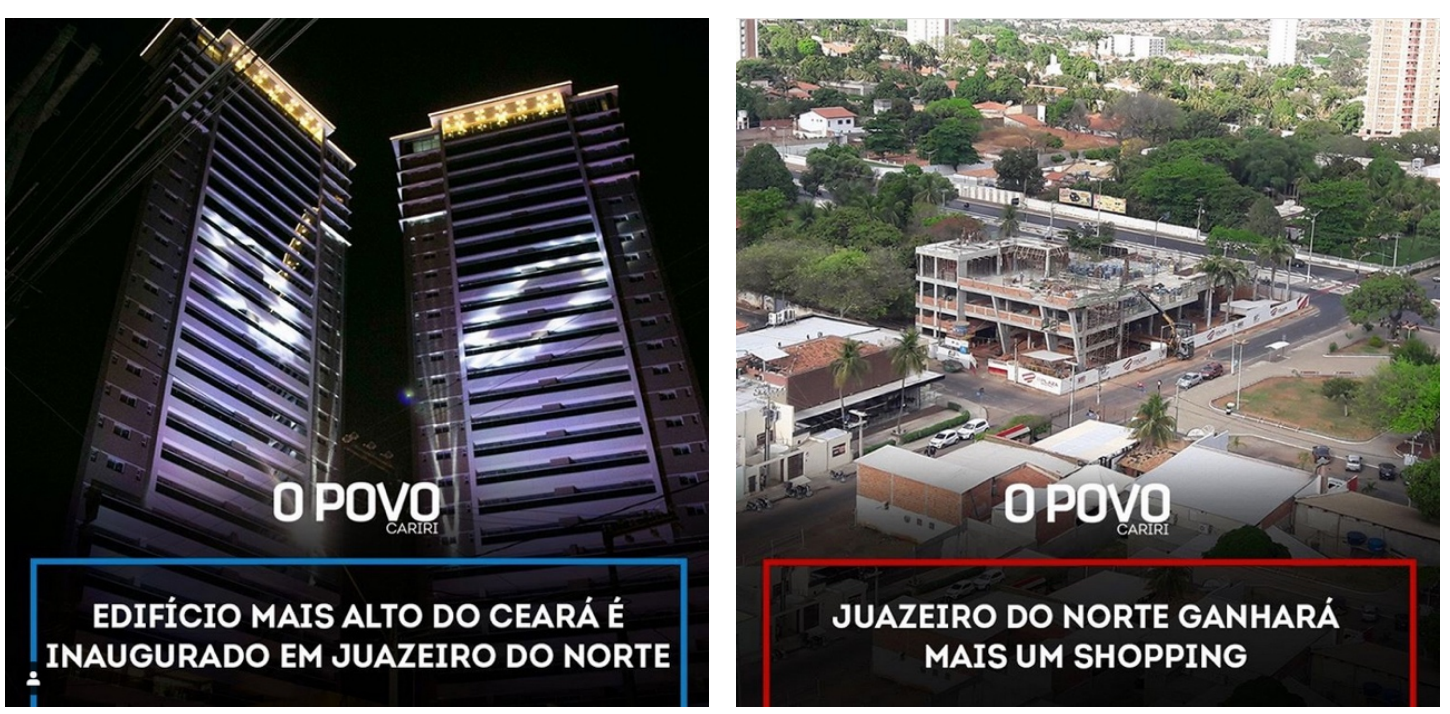

Figura 3: 0 edifício mais alto. Fonte: O Povo Cariri (29 nov. 2018) Figura 4: Mais um shopping. Fonte: O Povo Cariri (18 dez. 2018)

Dossiê Espaço Urbano e Imaginação Cultural - https://revistaecopos.eco.ufrj.br/

ISSN 2175-8689 - v. 22, n. 3, 2019

DOI: $10.29146 /$ eco-pos.v22i3.27412 
"Urbanidade", "modernidade", "metrópole", "arquitetura", "desenvolvimento", "símbolos marcantes", são algumas ideias que, nas palavras dos profissionais, estão discursivamente vinculadas à comunicação proposta pela logo da gestão municipal. Por outro lado, imagens midiáticas anunciadas por veículos locais também repercutem a imagem urbana associada às altas torres, tanto para fins residenciais quanto para comerciais, dando continuidade à imagem e discursos de desenvolvimento urbano e econômico estimulados pela logo. A atualidade da imagem urbana de Juazeiro, ao lado da religiosidade, está representada nos traços modernos do Unique Condominium, elemento central da marca da Prefeitura, e continuam a fazer parte da paisagem urbana atual. A partir disso, percebe-se um esforço governamental de branding urbano cuja finalidade é a invenção de uma imagem da cidade vendável e lucrativa, baseada em representações e repertórios do lugar que, neste caso, engloba a ideia de desenvolvimento urbano e econômico.

A variação de signos urbanos icônicos (McQuire, 2010; Peixoto, 2004; Ferrara, 2000) na construção comunicacional da cidade, apontando para a modernidade arquitetônica e de símbolos visuais marcantes, ressalta aspectos de desenvolvimento e progresso, ostensivamente conectados aos padrões hegemônicos globais. A imagem urbana do interior, na metrópole do Cariri cearense, vincula-se a marcos visuais em favor da "invenção" de uma cidade competitiva e conectada à ideia de "urbe", de "grandes metrópoles". Essa imagem, aqui sendo pensada por marcos como Luzeiro e Unique que comparecem na marca da gestão municipal, assinala que o imaginário popular e local ligado a Padre Cícero não é exclusividade na sustentação do Juazeiro moderno.

\section{Considerações finais}

A reinvenção da imagem da cidade de Juazeiro do Norte, no interior cearense, inclui esforços de branding na valorização de aspectos que vão além da

\section{Dossiê Espaço Urbano e Imaginação Cultural - https://revistaecopos.eco.ufrj.br/ \\ ISSN 2175-8689 - v. 22, n. 3, 2019 \\ DOI: 10.29146/eco-pos.v22i3.27412}


figura popular de Padre Cícero. Pelos signos icônicos da marca da Prefeitura de Juazeiro do Norte, Luzeiro e Unique trazem representações distintas e apartadas da prática e imaginário sociais. Eles são marcos visuais mais recentes da paisagem urbana, sendo o principal deles, inclusive, um empreendimento imobiliário de iniciativa privada (o Unique). Esse apartamento de representações e práticas sociais se conecta ao pensamento de Peixoto (2004), quando critica os aspectos cenográficos e de simulacro da estetização dos espaços. Do ponto de vista urbanístico, é crítica a falta de uso social de espaços tornados símbolos. Do ponto de vista comunicacional, é problemática a exclusão de consulta pública na construção de marca de uma gestão também pública.

Indo além de repertórios do turismo religioso local (Padre Cícero, Igreja do Socorro e Memorial), os marcos arquitetônicos e símbolos visuais imponentes (Luzeiro e Unique) surgem para comunicar o sentido de uma cidade associada ao crescimento e transformações urbanas na paisagem. Esta comunicação está vinculada a representações visuais que vieram até mesmo de fora do país, como destacou a assessora em entrevista e como foi descrita a inspiração do Unique em cidades como Dubai, o que confirma o desejo da gestão municipal em traduzir Juazeiro do Norte por repertórios urbano-imagéticos globalizados. A representação da "urbe" por meio de traços modernos "reconhecíveis" sublinha a ideia de criação do "espaço-mercadoria" (Sánchez, 2010), em que signos de "mundialidade" são produzidos para consumo.

A comunicação urbana, aqui pensada por meio de estratégias de construção da marca e por imagens midiáticas, desafia o pensamento crítico quanto à representatividade do lugar. É possível “empacotar" uma imagem vendável da cidade sem recorrer a signos socialmente partilhados? É possível projetar uma imagem de desenvolvimento urbano sem exclusão de repertórios populares locais? Ao pensar no caso de Juazeiro do Norte, estrategicamente, signos da religiosidade local se mantiveram junto a novos ideários de "metrópole". A imagem de desenvolvimento manifesta pelos traços modernos das construções 
(acontecimentos no espaço) não se aproxima do vínculo de experiência que os habitantes têm com esses lugares. Isso indica que, ao passo que se sintetiza uma cidade em cinco ícones, excluem-se outros potencialmente comunicáveis em nome de desejos de consumo aliados à imagem urbana que cresce verticalmente, desbravando o infinito celeste.

\section{Referências bibliográficas}

ARAÚJO, Maria de Lourdes. A cidade do Padre Cícero: trabalho e fé. Fortaleza: Editora IMEPH, 2011.

CACCIARI, Massimo. A cidade. Barcelona: Gustavo Gili, 2010.

FERRARA, Lucrécia. Os significados urbanos. São Paulo: Edusp: Fapesp, 2000.

GUERREIRO, Rúben Emanuel Campôa. Branding urbano: a revitalização urbana na construção da identidade da cidade [Tese de Mestrado]. Lisboa: FA. 2013.

JAGUARIBE, Beatriz. Imaginando a "cidade maravilhosa". Revista Famecos, Porto Alegre, v. 18, n. 2, p. 327-347, maio/ago, 2011.

MCQUIRE, Scott. The Media City: media, architecture and urban space. London: Sage Publications, 2010.

MORENO, Óscar Julián Cuesta; MELÉNDEZ-LABRADOR, Sandra. Comunicación urbana: antecedentes y conguración de líneas de investigación en América Latina y España. Territorios, Bogotá, 37, p. 205-228, 2017.

NETO, Lira. Padre Cícero: poder, fé e guerra no sertão. São Paulo: Companhia das Letras, 2009.

PEIXOTO, Nelson Brissac. Paisagens urbanas. São Paulo: Senac, 2004.

SÁNCHEZ, Fernanda. A reinvenção das cidades para um mercado mundial. Chapecó, PR: Ed. Argos, 2010. 